\title{
TINGKAT PENGETAHUAN KESEHATAN REPRODUKSI PADA SISWA SMA KANJENG SEPUH GRESIK
}

\author{
Wiwik Afridah $^{1}$, Ratna Fajariani ${ }^{2}$ \\ 1Prodi S1 Ilmu Kesehatan Masyarakat, Fakultas Kesehatan, \\ 2Prodi S1 Ilmu Kesehatan Masyarakat, Fakultas Kesehatan Universitas Nahdlatul Ulama Surabaya \\ Email:wiwik@gmail.ac.id
}

\begin{abstract}
Background: Adolescence is a transitional period between the time of children with adulthood. There are still many found little regard for teens on health on reproductive, will consequently risk against the occurrence of an increase in diseases, among others; Sexually Transmitted Infections (STI). Methods: This type of research is the pre-design experiments using One-Shot Case Study, measured through a questionnaire. Class X student population of 33 students, XI IPS 2 of 26 students, and XII IPS 1 of 29 students. With a variable level of knowledge about reproductive health education, sexually transmitted diseases, prevention and the introduction of infectious disease symptoms, processed and analyzed using descriptive statistics. Results: The results of the research on reproductive health education on class X most $(63,64 \%)$ have moderate levels of knowledge about sexually transmitted diseases in class XI IPS 2 most (73\%), 8 have a level of knowledge, level of knowledge about the prevention of infectious diseases and the introduction at the XII 1st most IPS $(58,62 \%)$ have moderate levels of knowledge. Conclusion: the level of knowledge of students of SMK Kanjeng Sepuh Gresik about adolescent reproductive health is on a category of being. Therefore the expected reproductive and Sexual health education as a subject/local content through the media of the school as a proper step as a medium of education can provide information on sexual and reproductive health is right for teens.
\end{abstract}

Keywords: Knowledge, Youth, Reproductive Health.

\section{PENDAHULUAN}

Masa remaja merupakan salah satu periode dari perkembangan manusia. Masa ini merupakan masa perubahan atau peralihan dari masa kanak-kanak ke masa dewasa yang meliputi perubahan biologi, perubahan psikologi, dan perubahan sosial. Di sebagian masyarakat dan budaya masa remaja pada umumnya dimulai pada usia 10-13 tahun dan berakhir pada usia 18-22 tahun. Menurut World Health Organization (WHO), remaja merupakan individu yang sedang mengalami masa peralihan yang secara berangsur-angsur mencapai kematangan seksual, mengalami perubahan jiwa dari jiwa kanak-kanak menjadi dewasa, dan mengalami perubahan keadaan ekonomi dari ketergantungan menjadi relatif mandiri. Mohammad (1994) mengemukakan bahwa remaja adalah anak berusia 13-25 tahun, di mana usia 13 tahun merupakan batas usia pubertas pada umummnya, yaitu ketika secara biologis sudah mengalami kematangan seksual dan usia 25 tahun adalah usia ketika mereka pada umumnya, secara sosial dan psikologis mampu mandiri.

Berbagai masalah yang ada pada remaja sangat rentan terhadap kesehatan reproduksi. World Health Organization (WHO) mendefinisikan bahwa kesehatan reproduksi merupakan suatu keadaan fisik dan mental serta sosial yang utuh, bukan hanya bebas dari penyakit atau kecacatan dalam segala aspek yang berhubungan dengan sistem reproduksi, fungsi, serta prosesnya. Sehat secara reproduksi merupakan suatu keadaan manusia dapat menikmati kehidupan seksualnya dan mampu menjalankan fungsi serta proses reproduksinya secara sehat dan aman.Usia remaja merupakan usia yang paling rawan mengalami masalah kesehatan reproduksi seperti kehamilan dan melahirkan usia dini, aborsi yang tidak aman, infeksi menular seksual (IMS) termasuk Human Immunodeficiency Virus (HIV), pelecehan seksual dan perkosaan. Jumlah remaja yang tidak sedikit merupakan potensi yang sangat berarti dalam melanjutkan pembangunan di 
Indonesia. Menurut survei demografi dan kesehatan Indonesia remaja (SDKI-R) tahun 2007,penduduk usia remaja perlu mendapat perhatian serius karena remaja termasuk dalam usia sekolah dan usia kerja, mereka sangat berisiko terhadap masalah-masalah Kesehatan reproduksi yaitu perilaku seksual pranikah, Napza dan HIV/AIDS (BKKBN, 2011).

Menurut Badan Kordinasi Keluarga Berencana Nasional (BKKBN 2010), diketahui sebanyak 51\% remaja di Jakarta, Bogor, Depok, Tangerang, dan Bekasi (Jabodetabek) telah melakukan hubungan seks pranikah. Dari kota-kota lain di Indonesia juga didapatkan data remaja yang sudah melakukan seks pranikah tercatat $54 \%$ di Surabaya, $47 \%$ di Bandung dan 52\% di Medan. kesehatan reproduksi. untuk mengetahui hal tersebut, perlu dilakukan penelitian mengetahui gambaran tingkatpengetahuan kesehatan reproduksi tentang pendidikan kesehatan reproduksi pada remaja, penyakit menular seksual dan pencegahan penyakit menular seksual pada siswa SMA Kanjeng Sepuh Gresik.

\section{METODE}

Desain penelitian kuantitatif, dengan menggunakan One-Shot Case Study, suatu kelompok diberi perlakuan dan selanjutnya diobservasi hasilnya. Populasi yaitu seluruh siswa dengan sampling purposive. Sampel yang digunakan yaitu siswa SMA Kanjeng Sepuh Gresik kelas X berjumlah 33 siswa, XI IPS 2 berjumlah 26 siswa, dan XII IPS 1 berjumlah 29 siswa.

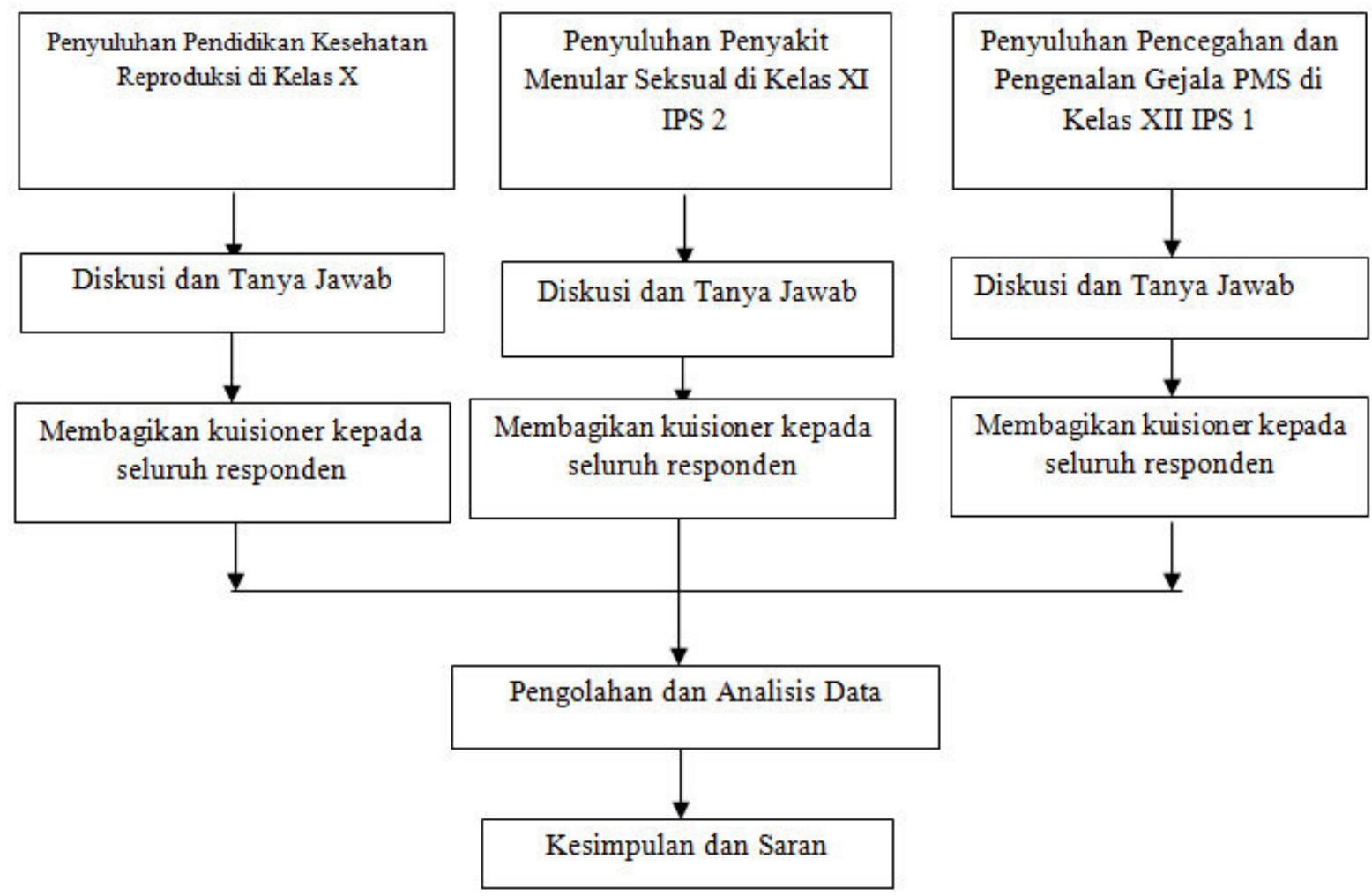

Oleh karena itu, topik program kesehatan reproduksi remaja merupakan topik yang perlu diketahui oleh masyarakat khususnya para remaja agar mereka memiliki informasi yang benar mengenai proses reproduksi serta berbagai faktor yang ada di sekitarnya. Dengan informasi yang benar, diharapkan remaja memiliki sikap dan tingkah laku yang bertanggung jawab mengenai

\section{HASIL}

A. Tingkat Pengetahuan Pendidikan Kesehatan Reproduksi

Penyuluhan ini diikuti oleh 33 siswa kelas X SMA Kanjeng Sepuh Gresik. Setelah penyuluhan, responden diberikan kuisioner post test untuk 
mengetahui tingkat pengetahuan responden terhadap materi yang sudah diberikan. Berikut merupakan tabel yang menggambarkan tingkat pengetahuan respoden tentang pendidikan kesehatan reproduksi.

Tabel 1. Distribusi Frekuensi Tingkat pengetahuan Responden tentang Pendidikan Kesehatan Reproduksi di SMA Kanjeng Sepuh Gresik.

\begin{tabular}{llcc}
\hline No & $\begin{array}{c}\text { Tingkat Pengetahuan } \\
\text { Kesehatan Reproduksi }\end{array}$ & N & $\%$ \\
\hline 1 & Rendah & 3 & 9,09 \\
\hline 2 & Sedang & 21 & 63,64 \\
\hline 3 & Tinggi & 9 & 27,27 \\
\hline & JUMLAH & 33 & 100 \\
\hline
\end{tabular}

Data Primer, 2013

Tabel 1 menunjukkan bahwa dari 33 responden, sebagian besar responden $(63,64 \%)$ memiliki tingkat pengetahuan sedang.

B. Tingkat Pengetahuan Penyakit Menular Seksual

Materi penyuluhan tentang penyakit menular seksual diikuti oleh 26 siswa kelas XI IPS 2 SMA Kanjeng Sepuh Gresik. Kuisioner post test juga diberikan sebagai alat ukur pengetahuan responden.

Tabel 2. Distribusi Frekuensi Tingkat pengetahuan Responden tentang Penyakit Menular Seksual di SMA Kanjeng Sepuh Gresik.

\begin{tabular}{cccc}
\hline No & $\begin{array}{c}\text { Tingkat Pengetahuan } \\
\text { Penyakit Menular Seksual }\end{array}$ & N & $\%$ \\
\hline 1 & Rendah & 2 & 7,69 \\
\hline 2 & Sedang & 19 & 73,08 \\
\hline 3 & Tinggi & 5 & 19,23 \\
\hline & JUMLAH & 26 & 100 \\
\hline
\end{tabular}

Data primer, 2013.

Tabel 2 menunjukkan bahwa dari 26 responden, sebagian besar responden $(73,08 \%)$ memiliki tingkat pengetahuan sedang.

C. Tingkat Pengetahuan Pencegahan dan Pengenalan Penyakit Menular Seksual

Penyuluhan yang diikuti oleh 29 siswa kelas XII IPS 1 SMA Kanjeng Sepuh Gresik yaitu tentang pencegahan dan pengenalan gejala penyakit menular seksual. Post test diberikan melalui kuisioner untuk mengetahui tingkat pengetahuan responden setelah mengikuti penyuluhan. Berikut gambaran tingkat pengetahuan responden yang disajikan dalam tabel 3.

Tabel 3. Distribusi Frekuensi Tingkat pengetahuan Responden tentang Pencegahan dan Pengenalan Gejala Penyakit Menular Seksual di SMA Kanjeng Sepuh Gresik.

\begin{tabular}{llcc}
\hline No & $\begin{array}{c}\text { Tingkat Pencegahan dan } \\
\text { Pengenalan Gejala } \\
\text { Penyakit Menular } \\
\text { Seksual }\end{array}$ & N & $\%$ \\
& \multicolumn{2}{c}{. } & \\
\hline 1 & Rendah & 2 & 6,90 \\
\hline 2 & Sedang & 17 & 58,62 \\
\hline 3 & Tinggi & 10 & 34,48 \\
\hline & JUMLAH & 29 & 100 \\
\hline
\end{tabular}

Data Primer, 2013

Tabel 3 menunjukkan bahwa dari 29 responden, sebagian besar responden $(58,62 \%)$ memiliki tingkat pengetahuan sedang.

\section{TABULASI SILANG}

Hasil tabulasi silang tingkat pengetahuan tentang 1) pendidikan kesehatan reproduksi, 2) penyakit menular seksual dan 3) pencegahan dan pengenalan gejala penyakit menular seksual, didapatkan sebagai berikut:

Tabel 4 Tabulasi Silang Tingkat Pengetahuan Responden di SMA Kanjeng Sepuh Gresik

\begin{tabular}{|c|c|c|c|c|}
\hline & \multicolumn{3}{|c|}{ Tingkat Pendidikan } & \multirow[b]{2}{*}{ Total } \\
\hline & $\begin{array}{l}\text { REND } \\
\text { AH }\end{array}$ & SEDANG & TINGGI & \\
\hline materi & 3 & 21 & 9 & 33 \\
\hline kespro & 2 & 19 & 5 & 26 \\
\hline & 2 & 17 & 10 & 29 \\
\hline PMS & 7 & 57 & 24 & 88 \\
\hline $\begin{array}{l}\text { PPS } \\
\text { Total }\end{array}$ & & & & \\
\hline $\begin{array}{l}\text { lateri* } \\
\text { ount }\end{array}$ & Tingkat & Pengetahua & Cros & lation \\
\hline
\end{tabular}


Hasil tabulasi tersebut diatas, dapat digambarkan dalam grafik sebagai berikut:

Grafik 1. Gambaran tingkat pengetahuan respoden.

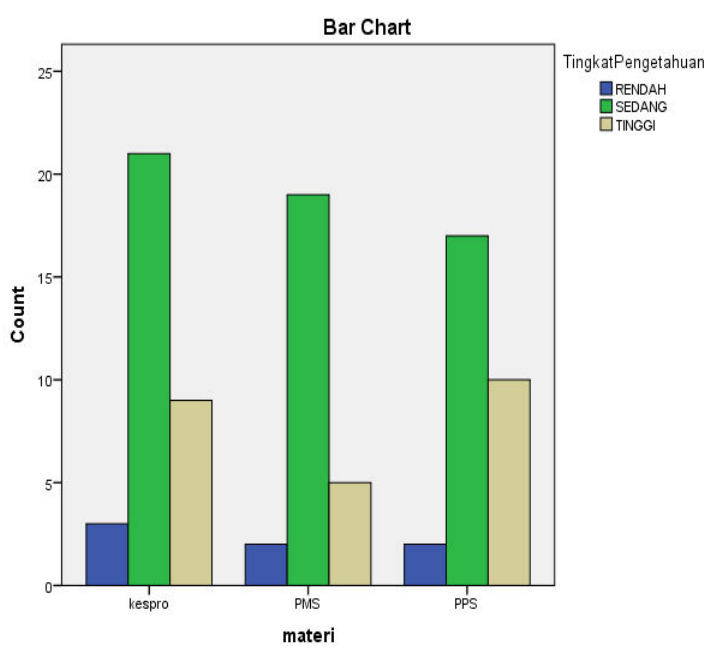

Berdasarkan grafik diatas dapat disimpulkan bahwa siswa dalam materi pendidikan kesehatan reproduksi telah memahami dengan baik dikarenakan tingkat pengetahuannya diatas rata-rata dibandingkan dengan materi PMS dan PPS tersebut.

\section{PEMBAHASAN}

A. Tingkat Pengetahuan tentang Pendidikan Kesehatan Reproduksi

Hasil penelitian yang dilakukan pada siswasiswi kelas X di SMA Kanjeng Sepuh Gresik menunjukkan bahwa siswa-siswi memiliki tingkat pengetahuan yang cukup.Berdasarkan tabel 1 didapatkan bahwa dari 33 responden, sebagian besar responden $(63,64 \%)$ memiliki tingkat pengetahuan sedang, mengenai konsep pubertas dan segala hal yang berkaitan dengan cara perawatan kesehatan terhadap organ reproduksi secara umum.

\section{B. Tingkat Pengetahuan Penyakit Menular Seksual}

Hasil penelitian yang dilakukan pada siswasiswi kelas XI di SMA Kanjeng Sepuh Gresik menunjukkan bahwa siswa-siswi memiliki tingkat pengetahuan yang cukup. Tabel 2 menunjukkan bahwa dari 26 responden, sebagian besar responden (73, 08\%) memiliki tingkat pengetahuan sedang, mengenai definisi PMS, meliputi pengertian PMS dan jenis PMS.

\section{Tingkat Pengetahuan Pencegahan dan \\ Pengenalan Penyakit Menular Seksual}

Hasil penelitian yang dilakukan pada siswasiswi kelas XII di SMA Kanjeng Sepuh Gresik menunjukkan bahwa siswa-siswi memiliki tingkat pengetahuan yang cukup. Tabel 3 menunjukkan bahwa dari 29 responden, sebagian besar responden (58, 62\%) memiliki tingkat pengetahuan sedang, mengenai cara pencegahan dan pengenalan terhadap penyakit menular seksual.

Menurut Notoatmodjo (2007) pengetahuan dipengaruhi oleh beberapa faktor yaitu: 1) sosial ekonomi, lingkungan sosial akan mendukung tingginya pengetahuan seseorang. Bila ekonomi baik, tingkat pendidikan tinggi maka tingkat pengetahuan akan tinggi pula; 2) kultur (budaya, agama), budaya sangat berpengaruh terhadap tingkat pengetahuan seseorang karena informasi yang baru akan disaring sesuai atau tidaknya dengan budaya yang ada atau agama yang dianut; 3) pendidikan, semakin tinggi pendidikan maka akan mudah menerima hal baru dan akan mudah menyesuaikan dengan hal baru tersebut; 4) pengalaman berkaitan dengan umur dan pendidikan individu. Pendidikan tinggi, maka pengalaman akan lebih luas, sedangkan semakin tua umur seseorang maka pengalamannya akan semakin banyak. Usia mempengaruhi terhadap daya tangkap dan pola piker seseorang. Semakin bertambah usia akan semakin berkembang pula daya tangkap dan pola pikirnya, sehingga pengetahuan yang diperolehnya semakin membaik.

\section{SIMPULAN}

Berdasarkan hasil penelitian dan pembahasan mengenai gambaran tingkat pengetahuan siswasiswi kelas X, XI dan XII SMA Kanjeng Sepuh Gresik, maka dapat diambil simpulan sebagai berikut: Tingkat Pengetahuan siswa-siswi kelas X, XI dan XII SMA Kanjeng Sepuh Gresik tentang Pendidikan Kesehatan Reproduksi, Penyakit Menular Seksual, dan Pencegahan dan Pengenalan Penyakit Menular Seksual memiliki tingkat pengetahuan sedang. 


\section{SARAN}

Berdasarkan hasil analisis dan simpulan yang didapatkan dari hasil penelitian, penulis menyarankan: Pihak sekolah dapat lebih memperhatikan para siswa dan siswi tentang pendidikan Kesehatan Reproduksi khususnya pada Penyakit Menular Seksual, dan Pencegahan dan Pengenalan Penyakit Menular Seksual.

\section{DAFTAR PUSTAKA}

Adelina Maharani Tugestim, dkk. Gambaran Pengetahuan Remaja Putri Tentang Kesehatan reproduksi Remaja di SMA Mardisiswa Semarang. 2012. Karya Tulis Ilmiah. Akademi Kebidanan Ngudi Waluyo.

Arikunto.S. 2006. Prosedur Penelitian Suatu Pendekatan Praktik. Edisi VI. Penerbit Rineka Cipta. Jakarta.

Imron, Ali. 2012. Pendidikan Kesehatan Reproduksi Remaja. Yogyakarta; ArRuz Media.

Mochamad I. Nurmansyah, Badra Al - Aufa, Yuli Amra. 2013. Gambaran Tingkat Pengetahuan Kesehatan Reproduksi Pada Mahasiswa Fakultas Kedokteran dan Ilmu Kesehatan UIN Jakarta. Jurnal BIMKMI Vol.I Nomor 2 Juni 2013.
Notoatmodjo. 2007. Promosi Kesehatan dan Ilmu Perilaku. Penerbit Rineka Cipta. Jakarta.

Nursalam. 2008. Konsep dan Penerapan Metodologi Penelitian Ilmu Keperawatan. Penerbit Salemba Medika.

Soetjiningsih. 2004. Buku Ajar Tumbuh Kembang Remaja dan Permasalahannya. Jakarta. Sagung Seto.

Wawan. A. 2011. Teori \& Pengukuran Pengetahuan, Sikap dan Perilaku Manusia. Yogyakarta. Nuha Medika.

Widyastuti, dkk. 2009. Kesehatan Reproduksi. Yogyakarta; Fitramaya. 